\title{
The role of parents and non-parents in the supervision of learner drivers in Australia
}

\section{Keywords}

Learner driver; young driver; graduated driver licensing; supervised driving requirements; parents; supervisors; siblings

\section{Introduction}

The introduction of Graduated Driver Licensing (GDL) systems has been associated with a reduction in crash risk for young novice drivers (Lyon, Pan, \& Li, 2012; Shope, 2007; Williams, Tefft, \& Grabowski, 2012). One of the key features of many GDL systems is that they require practice to occur over an extended period of time while the novice driver is driving on a learner licence (Bates, Watson, \& King, 2006).

Supervised driving practice allows learner drivers to obtain driving experience in a low risk manner (Hedlund, 2007). Spending more time on a learner licence, driving under supervision, decreases crash risk once the novice driver obtains an intermediate licence. In contrast, research suggests that driving unsupervised on a learner licence is associated with increased crash risk for individuals once they commence driving on an intermediate licence (Gulliver, Begg, Brookland, Ameratunga, \& Langley, 2013).

Several GDL systems require learners to complete a mandated number of hours of supervision before they are able to progress to an intermediate licence with specific requirements varying between jurisdictions. For instance, within the United States of America the required hours of practice varies between 20 hours in both Texas and Iowa to 65 hours in Pennsylvania (Insurance Institute for Highway Safety, 2012). However, Australian jurisdictions typically require learner drivers to undertake a significantly greater amount of practice. In Queensland, learner drivers need to accrue 100 hours of supervised practice 
recorded in a log book while those from New South Wales need to accrue 120 hours of supervised practice in their log book (Bates, Watson, \& King, 2010). By requiring learners to obtain a certain number of supervised hours of driving practice, there is an implicit assumption that private supervisors, such as parents, will be involved in the learning to drive process. For example, once the number of hours becomes relatively high, it is unlikely that they can be achieved by solely using professional instructors. The involvement of private driving supervisors, as opposed to professional driving instructors, enables the learner driver to accumulate a significantly higher amount of supervised driving hours (Tronsmoen, 2011). However in jurisdictions that require significant amounts of supervised practice, it may be difficult for parents to provide all of this practice. Thus, we need to gain an understanding of all sources of supervisors for learner drivers.

Drivers in both New South Wales and Queensland must hold their learner licence for a minimum of 12 months and complete their driving under supervision. Learner drivers in Queensland must record 100 hours of supervised driving in a log book and those in New South Wales must record 120 hours. Learner drivers in Queensland need to complete 10 hours of driving at night, while this requirement in New South Wales is 20 hours. Queensland learners who receive supervision from a professional driving instructor can record three hours for each actual hour of supervised practice up to a maximum of 10 hours of actual supervision or 30 hours being recorded in the log book. At the time the research was conducted, there was no comparable requirement in New South Wales. Thus, Queensland learners, in some circumstances, were eligible to undertake the practical driving test after completing only 80 hours of actual practice (Scott-Parker, Bates, Watson, King, \& Hyde, 2011; Scott-Parker, Watson, King, \& Hyde, 2011; Senserrick, 2007, 2009).

A significant amount of research has considered the involvement of parents in supervised driving including the amount of supervised driving practice provided to learner drivers by 
parents and friends (Bates, Watson, \& King, 2008, 2009a, 2009b; Bates et al., 2010; Jacobsohn, Garcia-Espana, Durbin, Erkoboni, \& Winston, 2012; Scott-Parker, Bates, et al., 2011) and parental awareness of supervised driving hours requirements (O'Brien, Foss, Goodwin, \& Masten, 2013). Parents are more likely to be the primary supervisors of learner drivers (Goodwin, Foss, Margolis, \& Waller, 2010; Scott-Parker, Bates, et al., 2011; Taubman-Ben-Ari, 2011). Research suggests that parents are supportive of GDL systems and that very few parents find the requirement to supervise their learner driver significantly inconvenient (Brookland \& Begg, 2011).

Parents are important influences on the driving experiences and behaviours of their children. They provide a role model for driving behaviour both before and after their children start driving (Taubman-Ben-Ari, 2010, 2011). Additionally, there are similarities between parents and their children in terms of driving style (Miller \& Taubman-Ben-Ari, 2010; TaubmanBen-Ari, Mikulincer, \& Gillath, 2005). Therefore, parents should be encouraged to act as good role models for their children not only when they are learners but before they obtain a licence (Scott-Parker, Bates, et al., 2011; Scott-Parker, Watson, \& King, 2009; Scott-Parker, Watson, King, \& Hyde, 2012).

While there has been research regarding the role of parents in supervised driving practice, there has been limited research into the role that other individuals, who have a different relationship with a learner driver, play in supervised driving practice. This paper addresses this research gap by considering who, apart from parents, supervises learner drivers even if they were not the primary supervisor. This paper focuses on private supervisors and thus does not consider professional driving instructors. The objectives of this paper are to identify who, apart from parents, is a private supervisor of a learner driver and whether there are differences in the perceptions and experiences between parental and non-parental private supervisors. This paper considers whether there are differences between the different types of 
relationships that private supervisors have with learner drivers from two Australian jurisdictions (Queensland and New South Wales) on a number of measures including: whether participants were first time supervisors; whether participants were the primary supervisor; the amount of supervised practice provided; perceptions about parental involvement in the learning to drive process and perceptions regarding the level of difficulty associated with the time and task of supervising a learner driver.

\section{Method}

\subsection{Participants}

The sample consisted of 522 supervisors of learner drivers from Queensland and New South Wales. Participants were recruited using a combination of convenience and snowball sampling techniques. The use of both techniques, while not random, enabled the inclusion of a wider range of supervisors of learner drivers within the sample. Recruitment occurred by delivering flyers requesting participation to letter boxes and asking participants, after they had completed the survey, to forward the survey link to other supervisors they knew and believed might be interested in participating. Given many of the similarities between the Queensland and New South Wales GDL systems, participants from both states were combined into one sample. Participants were asked if they had supervised a learner driver in the past 12 months and where they lived. If participants advised that they had not supervised a learner driver in the past 12 months or that they lived outside of Queensland or New South Wales, they were not eligible to complete the survey.

\subsection{Procedure}

Participants completed an internet survey that was open for completion between July 2009 and May 2010. After clicking on the survey link available on the flyer, and prior to 
completing the internet survey, participants were provided with information regarding the study on the initial screen of the survey. Participants provided their consent when they submitted their completed questionnaire. The internet survey took approximately 15 to 20 minutes to complete. Participants could elect to provide their contact details at the conclusion of the survey in order to receive a \$20 shopping voucher to reimburse them for their time. The study was undertaken with the approval of the Queensland University of Technology ethics committee.

\subsection{Statistical analysis}

Data was analysed using SPSS version 20. Chi-square tests were used for categorical data, and an adjusted standardised residual statistic was used as a post-hoc test. The adjusted standardised residual statistic indicates the cells that have an observed frequency that is significantly higher or lower than the expected frequency. The distribution of the adjusted standardised residual can be interpreted as a Z-score (Haberman, 1978). The strength of association between the categorical variables was measured using the Cramer's Phi $\left(\phi_{c}\right)$ coefficient. This coefficient provided an indication of effect size.

Parametric tests were used to analyse data collected by Likert scale, although this is not strictly interval data. This enabled the use of more sophisticated parametric analyses such as ANCOVA that would not have been possible using non-parametric tests. Eta-squared was used to provide an indication of effect size for the ANCOVAs. Where appropriate a Scheffe test was applied as a post-hoc analysis for the ANCOVAs. The significance level was set at .05 for all tests.

It is likely that characteristics like marital status, income and age are likely to vary in a systematic way across the different types of supervisors (for instance, sibling supervisors are likely to be consistently younger than parental supervisors). In other words, these differences 
are to a large extent likely to be inherent to each type of supervisor. Consequently, it was decided not to control for these differences in the analyses. However, in order to ensure that no bias was introduced due to the nature of the sample recruited in each state, it was decided to statistically control for this factor in the analyses (through the use of ANCOVA).

\section{Results}

\subsection{Sample}

Of the 522 participants in the sample, 204 were from Queensland and 318 from New South Wales. As shown in Table 1, there were no significant differences between different types of supervisors on the basis of gender. However, there were differences on the basis of marital status, income, age and state. Parents were more likely to be married, have higher incomes and be older when compared with other types of supervisors. There were more sibling and non family participants from New South Wales than from Queensland.

\section{INSERT TABLE 1 ABOUT HERE}

\subsection{Supervisor relationship to learner}

As shown in Table 2, the supervisors reported a range of differing relationships with the learner drivers. The most frequent relationships reported was being the mother (27.4\%), friend $(19.7 \%)$ or father $(15.9 \%)$ of the learner that they had supervised. The least frequent relationships reported by participants within this study were business associate $(0.2 \%)$ or parent in law $(0.2 \%)$.

\section{INSERT TABLE 2 ABOUT HERE}

In order to facilitate further analysis, supervisors were combined into the following categories: parents, siblings, other family and non-family. Parental supervisors included 
mothers, fathers and step parents and were the biggest sub-group within the sample $(n=255$, 48.9\%). The siblings category included both siblings and step siblings and was $13.8 \%(n=$ 72) of the sample. Other family supervisors included aunts/uncles, sisters/brothers in law, partners, cousins, grandparents and parents in law $(n=81,15.5 \%)$. Non-family supervisors included foster/homestay parents, friends, work colleagues and business associates $(n=114$, $21.8 \%)$.

\subsection{First time supervisor}

For two-thirds of the sample, this was the first time that they had supervised a learner driver $(n=345,66.1 \%)$. The chi-square analysis identified that parents were more likely to have supervised a learner driver previously while siblings were more likely to be supervising a learner driver for the first time $\left(X^{2}(3)=14.13, p=.003, \phi_{c}=.16\right)$. Within the sample, $40.4 \%$ of parents had supervised a different learner driver previously $(n=103)$ while $59.6 \%(n=$ 152) were supervising a learner driver for the first time. In comparison, $81.9 \%(n=59)$ of siblings were supervising for the first time while $18.1 \%(n=13)$ had previous supervision experience. The chi-square did not identify any significant differences in whether other family members or non-family members were first time supervisors. For $65.4 \%(n=53)$ of other family members and $71.1 \%(n=81)$ of non-family supervisors, this was the first time that they had supervised a learner driver.

\subsection{Primary supervisor}

Parents are more likely to be the primary supervisor of a learner driver when compared with siblings and non-family members $\left(X^{2}(3)=104.12, p<.001, \phi_{c}=.45\right)$. Over two-thirds of parents within the sample $(68.8 \%, n=174)$ indicated that they were the primary supervisor of the learner driver. This compares with $20.8 \%(n=15)$ of siblings, $41.3 \%(n=33)$ of other 
family members and $19.3 \%(n=22)$ of non-family who indicated that they were the primary supervisor of the learner driver.

\subsection{Other supervisors}

As shown in Table 3, the most common other supervisors reported were another parent and a professional driving instructor.

\section{INSERT TABLE 3 ABOUT HERE}

Supervisors that were other family members $(n=21,25.9 \%)$ were more likely to report that their learner driver did not spend time with a professional driving instructor $\left(X^{2}(3)=11.01\right.$, $\left.p=.012, \phi_{c}=.15\right)$ when compared with parents $(n=34,13.3 \%)$, siblings $(n=8,11.1 \%)$ and non-family $(n=12,10.5 \%)$. Additionally, a chi-square analysis revealed that parents were more likely to pay for their learner driver's professional driving lessons when compared with the other supervision groups $\left(X^{2}(6)=2.15 .5, p<.001, \phi_{c}=.49\right)$. Parents were more likely to pay for all lessons $(n=135,61.1 \%)$ or some lessons $(n=75,33.9 \%)$ when compared with siblings (all lessons: $n=16,25 \%$, some lessons: $n=8,12.5 \%$ ), other family (all lessons: $n=$ 15, 25\%, some lessons: $n=13,21.7 \%$ ) and non-family (all lessons: $n=11,10.8 \%$, some lessons: $n=6,5.9 \%)$.

\subsection{Amount of supervision provided}

Table 4 reports the amount of supervision that supervisors reported providing their learner driver. Supervisors reported providing an average of 56.52 hours of supervision $(s d=67.82)$ to their learner driver. Parents provided the highest average amount of hours $(M=65.17, s d=$ 62.26) while non-family supervisors provided the lowest average amount of hours $(M=$ 49.39, $s d=78.90$ ). Post hoc analysis identified that there was a significant amount of 
difference in the amount of practice provided by siblings when compared with parents and other family.

\section{INSERT TABLE 4 ABOUT HERE}

\subsection{Perceptions about parental involvement in learning to drive}

Participants were asked on a scale of 1 (not very involved) to 5 (very involved) how involved parents should be in the learning to drive process. An ANCOVA that controlled for state was conducted. Parents $(M=4.15, s d=.88)$, other family $(M=3.99, s d=.83)$, and siblings $(M=$ $3.93, s d=.92$ ) indicated that parents should have a strong involvement in learning to drive. However, non-family supervisors indicated that the parents should have a lower involvement $\left(M=3.68, s d=1.04 ; F(3,517)=8.33, p<.001, \eta^{2}=.05\right)$.

\subsection{Difficulty with time and task of supervision}

Participants reported how difficult it was for them to find time to provide the driving practice to learner drivers on a scale of 1 (very difficult) to 5 (very easy). They also indicated how difficult they found the task of providing supervised practice on the same scale. As shown in Table 5, participants indicated that it was difficult to find time to supervise learner drivers $(M$ $=2.84, s d=.89)$ and that the actual task of supervision was difficult $(M=2.92, s d=.87)$. Post hoc analysis identified that, when compared with other family members $(M=3.05, s d=$ $.97)$, parents reported greater difficulty in finding time to provide supervised practice $(M=$ $\left.2.70, s d=.91 ; F(3,517)=5.89, p=.001, \eta^{2}=.03\right)$. Parents $(M=2.76, s d=.91)$ also reported greater difficulty in the task of supervision when compared with siblings $(M=3.10$, $s d=.72)$ and non-family $\left(M=3.12, s d=.80 ; F(3,516)=7.73, p<.001, \eta^{2}=.04\right)$.

\section{INSERT TABLE 5 ABOUT HERE}

\section{Discussion}


While previous research has investigated the role of parents in providing supervised driving practice (Bates et al., 2008, 2009a, 2009b, 2010; Jacobsohn et al., 2012; Scott-Parker, Bates, et al., 2011), there has been limited consideration of the role of non-parents in the provision of supervised practice. As shown in this study, non-parents have an important role to play in supervising learner drivers even though they are not the primary supervisor in many cases. Within this study, supervisors reported a range of relationships to the learner driver including being their mother, father, friend, sibling, step parent, aunt or uncle, cousin, grandparent and partner. The largest group of supervisors within the study was mothers $(27.4 \%)$ which supports previous findings that highlight the role of mothers in the supervision of learner drivers (Goodwin et al., 2010; Scott-Parker, Bates, et al., 2011). However, there may be culture-related differences between jurisdictions in this regard with research from Israel indicating that fathers had the primary role when supervising new drivers (Taubman-Ben-Ari, 2011).

While other people may have provided supervision to the learner drivers, it was parental supervisors in both Queensland and New South Wales that were more likely to identify themselves as the primary supervisor of the learner driver. Parents were also frequently nominated as another person that provided supervision to the learner driver. Together these results indicate that parents have a strong involvement in the supervision of their learner driver in Australia. North American research has identified that frequently both parents are involved in the supervision of a learner driver with over two-thirds of the sample indicating that two parents provided supervision (Jacobsohn et al., 2012). The results of the current study thus confirm the important role of parents in providing learner drivers with sufficient supervised driving practice to meet licensing requirements.

The importance of parents in assisting learners to obtain supervised practice is reflected in the amount provided to learner drivers by each of the four supervisor types. Siblings provided 
fewer hours of practice when compared with parents, other family members and non-family members. However, once the median and modes are examined, it appears that parents who were participants in this study reported providing approximately half of the supervised practice required (median $=51$ hours). However, as this study found, participants that were identified as other family members made a substantial contribution to supervised practice ( median $=25$ hours), as did participants that were identified as siblings (median $=24.5$ hours) and non-family members (median $=15$ hours). Given that the licensing systems in both Queensland and New South Wales require significant amounts of supervised driving practice, the results suggest that learners may need to utilise all possible supervisors in order to accumulate sufficient driving hours. This may be one reason why siblings, other family members and non-family members are used as supervisors.

In this study, other family members reported that they found it easier to find the time to supervise learner drivers. Siblings and non-family found the actual task of supervising learner drivers easier than parents. Jacobsohn and colleagues (2012), in their North American research, found that parents identify the provision of supervised driving practice as a major time commitment with nearly 30 per cent of the sample reporting that it was 'somewhat hard' or 'hard' to find time to supervise a teenage driver. The findings of the current study may reflect the fact that concerned parents bear the responsibility of ensuring that their learner driver obtains sufficient and appropriate driving practice. Other types of supervisor do not have this responsibility and, thus, may find the task of supervision easier. It is also possible that non-parental supervisors take charge of the learner driver when they, as supervisors, have the time to do so. It may be seen as a bonus time for the learner driver rather than an expectation. Additionally, parents may be teaching more difficult elements of driving, particularly in the early phases of driving. This may be reflected in the fact they are reporting that they find the task of supervision more difficult than the other types of supervisors. 
Given that the introduction of extended supervised practice requirements places a burden on parents, it is crucial that there is parental support for the measure. While all participants indicated that parents should be involved in the learning to drive process, parents, other family members and siblings were more likely to report the need for extensive parental involvement. This finding extends previous research which, using a sample of parents from Connecticut, suggests that parents believe that they should be extensively involved in teaching their teenager to drive (Williams, Leaf, Simons-Morton, \& Hartos, 2006). Other authors have suggested the importance of parental involvement in the supervision of learner drivers (Toledo, Lotan, Taubman-Ben-Ari, \& Grimberg, 2012). This paper identifies that it is not just parents who believe they have a strong role in teaching their learner but also other family members and siblings.

This study also indicates the important role that professional driving instructors play in supervising learner drivers with approximately two-thirds of the sample indicating that a professional driving instructor was another supervisor of the learner driver. This is similar to the findings of the Jacobsohn and colleagues (2012) study in the United States of America where they identified a similar percentage of supervisors reporting that a professional driving instructor was used. This study identified that parents were more likely to pay for some or all of their learner's professional driving lessons when compared with other types of supervisor.

This study has identified that people other than parents have a key role to play in providing supervised practice to learner drivers. However further research is required to clarify why siblings, other family members and non-family members are becoming involved in the supervision of learner drivers and at what point in time in the process. Are non-parental supervisors supervising different types of learner drivers such as partners? Are parents aware that their learner is obtaining supervision from elsewhere? Are parents more involved at the beginning of the learning process and others later on? Consistent with this, are parents 
providing more instructional teaching while the other types of supervisors are providing driving practice?

This study has several limitations associated with the convenience and snowball sampling technique that was used. The use of this type of sampling technique made it impossible to calculate response rates to the survey. Additionally, a volunteer bias could be present within the study, for example, with those people participating who were more strongly interested in road safety. Finally, the representation of the four types of supervisors within the study may not be generalisable to the broader population. However, the use of a convenience and snowball sample allowed the researchers access to a broader range of supervisors than have traditionally been used in young driver research. Therefore, the researchers were able to identify that supervisors who are not parents have a role to play in providing supervised driving practice to learner drivers. In addition, an attempt was made to control for the differences across participants. However, replication of this research with a probability sample would overcome many of the limitations associated with the sampling technique. Another limitation associated with this study was the reliance on self-report data which may lead to some concerns regarding the validity of the data. However, the use of self-report data in this study allowed researchers to obtain information, such as the perceptions and beliefs of participants, that would have been difficult to obtain by other means. Further research regarding different types of supervisors of learner drivers should help to overcome this limitation.

It appears that, at least in jurisdictions that require 100 or 120 hours of practice, supervisors who are not parents have an important role to play in providing supervised driving practice. This suggests that policy makers need to consider if the involvement of these types of supervisors is desirable and if programs and policies need to involve them. Many initiatives, 
such as the required driver orientation course for parents in Connecticut, are aimed at parents of learner drivers (Chaudhary, Williams, \& Casanova, 2010). This course is a 2 hour class for both the prospective learner driver and their parent or legal guardian. The prospective learner driver then attends additional driver education without their parent or legal guardian. The course is compulsory for 16 and 17 year olds who want to obtain a learner license. Given the amount of supervision provided by non-parents, there may be a need to consider if these types of programs should be available to non-parents.

Additionally, encouraging learners to seek additional supervision from alternative supervisors such as siblings, other family members and non-family may help to reduce the difficulty that parental supervisors perceive regarding finding time to provide supervised driving. This may help to reduce the pressure and responsibility that some parents may associate with providing supervised driving practice.

\section{Conclusion}

This study has identified that the supervision of learner drivers, at least in jurisdictions which mandate either 100 or 120 hours of supervised driving practice, involves more supervisors than just parents including siblings, other family members and non-family. Parents were more likely to be the primary supervisor of the learner driver and more likely to pay for professional driving lessons indicating that they carry the responsibility of ensuring that their children meet the requirements of the learner licence.

\section{Acknowledgements}

The authors acknowledge the financial assistance of the Queensland Motor Accident Insurance Commission and the Institute for Health and Biomedical Innovation for this study. The authors also acknowledge the assistance of Mr Michael Bates and Ms Jenny Bennett in 
the recruitment of participants for this study. Additionally, we thank the anonymous reviewers who provided feedback on an earlier version of this paper.

\section{References}

Bates, L., Watson, B., \& King, M. (2006). Competing or Complementing: Driver Education and Graduated Driver Licensing. Paper presented at the Road Safety Research, Policing and Education Conference, Gold Coast.

Bates, L., Watson, B., \& King, M. (2008). The structure of the learner licence affects the type of experiences novices gain during this phase: Examples from Queensland and New South Wales. Journal of the Australasian College of Road Safety, 19(4), 36-42.

Bates, L., Watson, B., \& King, M. (2009a). Driving and licensing experiences of learner drivers in two Australian states prior to changes in the licensing laws. Journal of the Australasian College of Road Safety, 20(3), 51-55.

Bates, L., Watson, B., \& King, M. (2009b). Factors influencing learner driver experiences. Canberra: Department of Infrastructure, Transport, Regional Development and Local Government.

Bates, L., Watson, B., \& King, M. (2010). Required hours of practice for learner drivers: A comparison between two Australian jurisdictions. Journal of Safety Research, 41, 9397.

Brookland, R., \& Begg, D. J. (2011). Adolescent, and their parents, attitudes towards graduated driver licensing and subsequent risky driving and crashes in young adulthood. Journal of Safety Research, 42(2), 109-115.

Chaudhary, N., Williams, A., \& Casanova, T. (2010). Parents' attitudes about Connecticut's required driver orientation course for parents. Traffic Injury Prevention, 11(5), 478482. 
Goodwin, A. H., Foss, R., Margolis, L. H., \& Waller, M. (2010). Parents, teens and the learner stage of graduated driver licensing. Washington: AAA Foundation for Traffic Safety.

Gulliver, P., Begg, D., Brookland, R., Ameratunga, S., \& Langley, J. (2013). Learner driver experiences and crash risk as an unsupervised driver. Journal of Safety Research, 46, 41-46.

Haberman, S. (1978). Analysis of qualitative data. Vol 1: Introductory topics. New York: Academic Press.

Hedlund, J. (2007). Novice teen driving: GDL and beyond. Journal of Safety Research, $38(2), 259-266$.

Insurance Institute for Highway Safety. (2012). Young driver licensing systems in the U.S. . Retrieved 18 September, 2012, from http://www.iihs.org/laws/graduatedlicenseintro.aspx

Jacobsohn, L., Garcia-Espana, J., Durbin, D. R., Erkoboni, D., \& Winston, F. K. (2012). Adult-supervised practice driving for adolescent learners: The current state and directions for interventions. Journal of Safety Research, 43(1), 21-28.

Lyon, J., Pan, R., \& Li, J. (2012). National evaluation of the effect of graduated driver licensing laws on teenager fatality and injury crashes. Journal of Safety Research, 43, 29-37.

Miller, G., \& Taubman-Ben-Ari, O. (2010). Driving styles among young novice drivers - The contribution of parental driving styles and personal characteristics. Accident Analysis \& Prevention, 42, 558-570.

O'Brien, N., Foss, R., Goodwin, A., \& Masten, S. V. (2013). Supervised hours requirements in graduated driver licensing: Effectiveness and parental awareness. Accident Analysis \& Prevention, 50, 330-335. 
Scott-Parker, B., Bates, L., Watson, B., King, M., \& Hyde, M. (2011). The impact of changes to the graduated driver licensing program in Queensland, Australia on the experiences of learner drivers. Accident Analysis \& Prevention, 43, 1301-1308.

Scott-Parker, B., Watson, B., \& King, M. (2009). Understanding the psychosocial factors influencing the risky behaviour of young drivers. Transportation Research Part F: Traffic Psychology and Behaviour, 12, 470-482.

Scott-Parker, B., Watson, B., King, M., \& Hyde, M. (2011). Mileage, Car Ownership, Experience of Punishment Avoidance, and the Risky Driving of Young Drivers,. Traffic Injury Prevention, 12(6), 559-567.

Scott-Parker, B., Watson, B., King, M., \& Hyde, M. (2012). “They're lunatics on the road'” Exploring the normative influences of parents, friends, and police on young novices' risky driving decisions. Safety Science, 50, 1917-1928.

Senserrick, T. (2007). Recent developments in young driver education, training and licensing in Australia. Journal of Safety Research, 38(2), 237-244.

Senserrick, T. (2009). Australian Graduated Driver Licensing Systems. Journal of the Australasian College of Road Safety, 20(1), 20-26.

Shope, J. T. (2007). Graduated driver licensing: Review of evaluation results since 2002. Journal of Safety Research, 38(2), 165-175.

Taubman-Ben-Ari, O. (2010). Attitudes toward accompanied driving: The views of teens and their parents. Transportation Research Part F: Traffic Psychology and Behaviour, 13, 269-276.

Taubman-Ben-Ari, O. (2011). The contribution of perceived parental and familial characteristics to attitudes toward accompanied driving among young drivers. Accident Analysis \& Prevention, 43(1720-1729). 
Taubman-Ben-Ari, O., Mikulincer, M., \& Gillath, O. (2005). From parents to children-similarity in parents and offspring driving styles. Transportation Research Part F: Traffic Psychology and Behaviour, 8(1), 19-29.

Toledo, T., Lotan, T., Taubman-Ben-Ari, O., \& Grimberg, E. (2012). Evaluation of a program to enhance young drivers' safety in Israel. Accident Analysis \& Prevention, $45,705-710$.

Tronsmoen, T. (2011). Differences between formal and informal practical driver training as experienced by the learners themselves. Transportation Research Part F: Traffic Psychology and Behaviour, 14, 176-188.

Williams, A., Leaf, W. A., Simons-Morton, B., \& Hartos, J. L. (2006). Parents' views of teen driving risks, the role of parents, and how they plan to manage the risks. Journal of Safety Research, 37, 221-226.

Williams, A., Tefft, B., \& Grabowski, D. C. (2012). Graduated driver licensing research, 2010-present. Journal of Safety Research, 43, 195-203. 